\title{
An innovative teaching approach to product development: creating tennis wear for female baby boomers
}

\author{
May Chae* (1)
}

\author{
*Correspondence: \\ chaem@montclair.edu \\ Department of Art \\ and Design, Montclair State \\ University, 1 Normal Ave, \\ Montclair, NJ 07043, USA
}

\begin{abstract}
To approach innovative teaching, prototype development of tennis wear for female baby boomers was incorporated into the product development course. This semesterlong project, fully funded by Cotton Incorporated, guided students in identifying the needs of female baby boomers who play tennis and then designing appropriate tennis wear. Twelve female tennis participants aged between 55 and 66 were interviewed in a focus group. To mirror fashion industry practice, students worked in teams including with real-world clients. The functional, expressive, and aesthetic consumer needs model (Lamb and Kallal in Cloth Text Res J 10:42-47, 1992) provided the conceptual framework for the project, and the students took the FEA design criteria into account when developing tennis wear prototypes that met the needs of the baby boomers. At the end of the semester, a panel of faculty judges who fall within the age group of baby boomers and who play tennis regularly evaluated the student groups' work and selected the three winning teams using the following criteria: creativity, quality (i.e., construction, tech pack [garment measurements], and fit), presentation (i.e., storyboard and oral presentation), and readiness for production.
\end{abstract}

Keywords: Innovative teaching, Industry practice, Baby boomers, Tennis wear, Prototype development

\section{Introduction}

Although it is challenging, creating new products is an important mission in the fastpaced fashion world. To promote a better understanding of how to creatively produce an apparel product from concept to consumer, a new project was designed to teach a product development course, which motivated the students through the use of an innovative teaching method. Innovative teaching helps students reach their full potential (Kibria 2014). In Domodharan and Rengarajan's study (2007), the use of innovative teaching methods has the potential not only to improve education, but also to empower students to achieve their development goal, while the traditional teaching methods result that there is insufficient interaction with students in classroom and gives a lack of any practical and real life time situations to students.

A product development process begins by identifying the potential target market. According to Keiser and Garner (2012), "Product developers and retailers expend a great

(C) The Author(s) 2017. This article is distributed under the terms of the Creative Commons Attribution 4.0 International License (http://creativecommons.org/licenses/by/4.0/), which permits unrestricted use, distribution, and reproduction in any medium, provided you give appropriate credit to the original author(s) and the source, provide a link to the Creative Commons license, and indicate if changes were made. 
deal of effort identifying consumers who have the potential to be regular customers. A target market is a well-defined customer group to which a business wants to sell" (p. 60). As part of an innovative teaching approach, the baby boomer target market was considered important to the project-as Green (2016) indicated, this influential over-50 segment has \$2.3 trillion in annual spending power and controls $50 \%$ of all discretionary income. In spite of this demographic group's growing size, however, retailers have expressed little interest in marketing to the mature market. The special target market for this project enabled us to inspire creative thinking for fashion students because this market is very different from the market for those students, which typically concentrates on fashion for young women.

Watkins (1988) stated that it is necessary for design educators to prepare students to become creative problem-solvers who are able to go beyond simple, deductive thinking. The design process proposed by Watkins can be a valuable lesson for fashion students; through this process of creative thinking, they can learn to apply systematic approaches to solving problems. The more students who follow the steps of the design process, the stronger their creativity and practicality will become.

The project, which was fully funded by Cotton Incorporated, guided students in identifying the needs of female baby boomers ( 55 and older) who play tennis and then designing their tennis wear. Therefore, The purpose of this study was twofold: (a) to assess the needs of female baby boomers regarding tennis wear to establish design criteria and (b) to develop prototypes of cotton tennis wear that incorporated the identified design criteria.

The specific objectives of this study were as follows: (a) to identify the clothing needs of female baby boomers who play tennis regularly, (b) to familiarize students with the features and benefits of cotton for active apparel using a semester-long product development assignment, and (c) to make student learning industry oriented.

\section{Literature review}

Who are baby boomers? According to Wikipedia (2017), baby boomers are defined as people who were born during the post-World War II baby boom. This group includes people who are between the birth years of 1946 and 1965. As a group, they were identified by Wikipedia as the wealthiest, most active, and most physically fit generation. They could reap the benefits of abundant levels of food, apparel, and retirement programs because they had received peak income levels. Therefore, this generation demonstrates significant annual spending power and discretionary income, which is similar to Green's (2016) statement regarding influential over-50 segment in the market.

\section{Clothing issues with female baby boomers: body changes, fit, and comfort}

Chae and Evenson (2013) mentioned that many active sportswear styles are inappropriate for the mature female body - the garments do not fit well or limit body movement. Zhang (2004) pointed out that older women are a potential market for activewear, but fit is complicated by the physical changes of the aging process. In general, the lack of a standardized sizing system in the current apparel industry results in insufficient industry attention being given to baby boomers' body changes (Lee et al. 2012). Several physical changes occur when a woman ages: stature becomes shorter, the waistline thickens, 
the abdomen becomes more prominent, the seat flattens, and there is a forward tilt of the head and shoulders (Chumlea et al. 1984; Goldsberry et al. 1996; Labat and Delong 1990; Reich and Goldsberry 1993; Rosenbald-Walin and Karlsson 1996). Khon (1996) highlighted the importance of providing well-fitting clothing for the older population because of their age-related body changes.

A poor fit has long been a major area of consumer dissatisfaction with ready-towear apparel, and this dissatisfaction was particularly evident among women aged 55 and older (Reich and Goldsberry 1993). Although clothing that fits properly is the most important consideration for older women when purchasing apparel, they typically experience difficulty in finding clothing that fits their body shape and styles appropriate for the aging body (Lee et al. 2012). Reich and Goldsberry (1993) found that $69 \%$ of women aged 55-74 were dissatisfied with the fit of ready-to-wear garments; indeed, fit was the dissatisfaction factor most commonly reported, especially clothing that was too tight in the abdomen, hips, thighs, waist, and crotch.

Sontag (1985) explained that physical comfort of clothing is "a mental state of physical well-being expressive of satisfaction with physical attributes of a garment such as air, moisture, and heat transfer properties, mechanical properties such as elasticity and flexibility, bulk, weight, texture, and construction" (p. 10). Sontag defined psychological comfort of clothing as "a mental state of psychological well-being expressive of satisfaction with desired affective states, such as femininity, sophistication, having fun, or aesthetic characteristics" (p. 10). Regardless of the type of sport being played, comfort could be one of the important factors in order to raise the performance of players (Mullet 1996). According to Cotton Incorporated's Lifestyle Monitor (2015), women responded that comfort (46\%) is their favorite feature of activewear, followed by fit (17\%), style (15\%), and breathability (15\%).

\section{Cotton preferences}

According to Cotton Incorporated's Lifestyle Monitor (2012), 77\% of consumers indicated that better quality garments are made from natural fibers. This response has gone up significantly from 2008 (69\%), 2009 (73\%), and 2010 and 2011 (75\%). Consumers prefer cotton for many of their apparel items. In fact, $71 \%$ of consumers want athletic wear made of cotton or a cotton blend.

Davis (1987) reported that overall preferences for fiber contents were as follows: cotton (38\%) and cotton blend (56\%) over polyester (14\%). Consumers perceived cotton as comfortable and easy to care for (Forsthe and Thomas 1989). Also, Chae and Evenson (2013) indicated that baby boomers often prefer natural fibers such as cotton for their comfort and easy care. In Forsythe and Thomas' (1989) study, the attributes of comfort, easy care, durability, luxuriousness, and practicality appeared to contribute the most influence to the first major component for cotton. Consumers may love cotton because it feels great against their skin; however, $100 \%$ cotton activewear is not ideal because natural fibers like cotton absorb and hold moisture (i.e., sweat; Feiereisen 2016). Many consumers think that cotton's functional performance in activewear is limited because when cotton gets wet, it becomes heavy and takes a long time to dry. This problem has been solved by a new technology called TransDRY. A Cotton Incorporated investment, TransDRY is a patented, high-performance moisture management application that allows 
fabrics to wick and spread perspiration as well as or better than most high-tech synthetic fabrics. Consumers get the comfort and softness of their favorite cotton T-shirt along with wicking and fast-drying performance (What is TransDry technology? 2016). This technology is an innovative development that enables cotton to improve its performance utility in activewear. Although cotton remains consumers' first choice for clothing (Robinson 2009), it does not appear to be manufacturers' first choice despite the invention of TransDRY.

\section{Teaching approach utilizing the baby boomers age and tennis wear}

To create an industry-like approach to product development, the course was specifically designed for the fashion students as follows: (a) working in groups throughout the semester, (b) working with real-world clients (i.e., female baby boomer tennis players), and (c) focusing on the specific product category (i.e., tennis wear made out of cotton/ cotton blends).

The baby boomer generation is not one to be ignored because it is the most active, health-conscious demographic in history. Furthermore, baby boomers are social animals who resist the idea of being sedentary (Sprecher 2005). The specific age group born around 1946-1965 affects the market. There are 79 million baby boomers in the United States now, and every day for the next 19 years, 10,000 people will turn 65 (Stone 2011). Therefore, preparing the changing marketplace for baby boomers is an important business for the fashion industry. Are fashion students prepared for a changing marketplace where they are faced with working with real-world clients? Teaching approaches to dealing with baby boomers could be an innovative way to motivate students to become active and confident when working with real-world clients.

Baby boomers are active. According to Stone (2011), the United States Tennis Association (USTA) tennis participation survey revealed interesting results: There are 27.8 million tennis players in the United States, which is about $9 \%$ of the overall population. About 3.42 million of that total, or $12 \%$, is 50 and older. Only $2 \%$ of all new players, or 101,000, are 50 and older. More than 700,000 USTA members $(\sim 9 \%)$ are aged 65 and older. "Boomers are the first generation that grew up exercising, and the first that expects, indeed demands, that they be able to exercise into their 70s" (Pennington 2006). Tennis is one of the most popular sports among baby boomers because they can have fun and stay fit.

Baker (1995) described inventing as creating, and innovating as valuing, introducing, and inventing. Lunde and Wilhite (1996) stated, "Innovative teaching is more than the light bulb that comes on when innovation occurs, more than going where no one has gone before" (p. 156). Lunde and Wilhite also mentioned that innovative teaching helps students by making them take responsibility for their own leaning by, usually, relying on active learning strategies and creating a safe classroom environment. Students can be more actively engaged in a class through innovative teaching. In other words, innovative teaching supports students in active learning. The benefits of active learning include better critical-thinking abilities; improved time management, interpersonal, and communication skills; and higher levels of student motivation (Salemi 2002). Innovative teaching can help students to think logically to promote their creativity. Problem-solving learning is student focused rather than instructor focused. Creativity and problem solving are 
closely related (Banning and Gam 2013). Schools must critically consider both educational programs and environments to encourage and enhance students' creative problemsolving abilities, skills that can lead to increased activities for students (Im et al. 2015). When teaching emphasizes active engagement, students tend to learn more positively and effectively. Teaching students utilizing a real-world situation with baby boomers in a product development class is one of the most effective teaching methods because it directs them to think beyond the younger target market with which they are mostly familiar. Therefore, identifying a needs assessment and developing tennis wear for female baby boomers could offer students an opportunity to get out of their comfort zone and find solutions for the clothing issues facing female baby boomers who play tennis. These activities keep the students interested and make learning relevant, interactive, and fun by providing both hands-on (e.g., physical) and minds-on (e.g., mental) instruction.

\section{Watkin's design process}

The Watkins design process (1988) is widely used in studies on clothing design (Bye and Hakala 2005; Krenzer et al. 2005; Lamb and Kallal 1992). The process comprises seven steps: (a) accept (identify the problem), (b) analyze (analysis of user needs and wants), (c) define (identify needs), (d) ideate (refine preliminary ideas), (e) select (choose prototype designs), (f) implement (develop prototypes), and (g) evaluate. Bye and Hakala (2005) used the Watkins process as a framework to guide the development of a specific sailing garment for women, and Krenzer et al. (2005) likewise utilized the process to develop a sports bra prototype. Lamb and Kallal (1992) also used the Watkins process to develop a framework for clothing design that incorporated functional, expressive, and aesthetic (FEA) aspects and emphasized developing problem-solving skills.

Pitimaneeyakul et al. (2004) conducted a case study of knitwear product development. According to these authors, Watkins argued that in the design process, designers must employ both cognitive and intuitive approaches. Pitimaneeyakul et al. described a product development procedure that adapted Watkins's process: accept the problem, analyze variables, define, generate ideas, and select and implement solutions. Implementation includes evaluating the developed designs (Pitimaneeyakul et al. 2004).

\section{Methods}

\section{Focus group}

Prior to conducting the focus group, the Institutional Review Board approved this study to assure the protection of human subjects, a requirement of all research at our university. We recruited 12 female baby boomers from the Mid-Atlantic region of the USTA to engage in a focus group interview for about an hour and voluntarily serve as fit models for the project throughout the semester. The participants' age ranged from 55 to 66 years, and the length of their participation in tennis ranged from 6 to 30 years.

We conducted focus group interview initially using Lamb and Kallal's (1992) functional, expressive, and aesthetic (FEA) consumer needs model to determine the target consumers' use needs. We further utilized Bye and Hakala's (2005) study to modify the questions for the project. For efficiency and effectiveness of data collection, we divided the original interview questions into the following subgroups: (a) difficulties and dissatisfaction with and current market situations for mature female tennis wear, (b) FEA 
needs, and (c) additional information (see Table 1). We then adapted Lamb and Kallal's proposed design process to create tennis wear that maximized the benefits and usefulness of cotton for these female customers. We explained the meanings of the FEA needs to the participants prior to the interview to aid in understanding of the FEA aspects so that they could be discussed confidently.

Students compiled interview questions that included or were based on the samples listed in Table 1. Each student group followed the design process, considering the responses to the interview questions, to develop ensembles for the target market using storyboards, flat-pattern/draping techniques, Adobe Photoshop and Illustrator techniques, test garments (fitting), and prototype ensembles made from fashion fabric that was either $100 \%$ cotton or a cotton blend $(70+\%$ cotton).

\section{Results}

One of the focus group participants offered her view of the market for female baby boomer tennis wear. Shelley Launey, a USTA member who works at a tennis club, explained, "Most outfits in the stores are geared to 20-somethings." She thought that retailers were missing out on a valuable market. She also pointed out that "many older women have more time to play than someone younger with family and work commitments."

The major findings of FEA needs for mature female tennis participants were as follows: (a) functional needs included comfort, fit, breathability, durability, free movement, utility, and protection from the sun; (b) expressive needs included self-esteem, age appropriateness, individuality, personality, and a professional look; and (c) aesthetic needs included a feminine and sporty look, a strong and powerful look, and a colorful, flattering, unique, and slimmer look.

\section{Functional}

Some of the most important needs for tennis wear among female baby boomers are relevant to functional aspects such as comfort, fit, breathability, durability, free movement, utility, and sun protection. Comfort and fit are critical elements. In the comments, participants said:

\section{Table 1 Focus group interview questions}

\begin{tabular}{|c|c|}
\hline \multirow{5}{*}{$\begin{array}{l}\text { A. Difficulties/dissatisfaction/ } \\
\text { current market situations }\end{array}$} & 1. Have you ever found it difficult to find suitable clothing? \\
\hline & 2. What is your usual motivation when buying new tennis garments? \\
\hline & $\begin{array}{l}\text { 3. Are there any specific areas where you are dissatisfied with the garments } \\
\text { that you have worn? }\end{array}$ \\
\hline & $\begin{array}{l}\text { 4. In the case of tennis wear you have worn and liked, what qualities or specific } \\
\text { design features did you like? }\end{array}$ \\
\hline & 5. How do you view the market for female baby boomer tennis garments? \\
\hline \multirow[t]{3}{*}{ B. FEA needs } & $\begin{array}{l}\text { 1. Could you describe the design criteria and garment attributes of tennis wear } \\
\text { for functional needs? }\end{array}$ \\
\hline & $\begin{array}{l}\text { 2. Could you describe the design criteria and garment attributes of tennis wear } \\
\text { for expressive needs? }\end{array}$ \\
\hline & $\begin{array}{l}\text { 3. Could you describe the design criteria and garment attributes of tennis wear } \\
\text { for aesthetic needs? }\end{array}$ \\
\hline \multirow[t]{3}{*}{ C. Additional information } & 1. What qualities do you look for in tennis wear? \\
\hline & 2. Where do you find you need the most flexibility in your garments? \\
\hline & 3. Is there anything else that you would like to add? \\
\hline
\end{tabular}


"I can't wear tight-fitting sleeves... feels like it's just pulling right up underneath my arms... uncomfortable..."

"Comfort comes first when I am buying tennis clothes..."

"... always pulling up and down... something's wrong..."

Free arm and shoulder movement was a critical factor for baby boomer tennis clothes, similar to the mature female golf clothes (Chae and Evenson 2013). In the comments, participants said:

"We do need free movement to swing the arm and hit the ball more cleanly..."

"... needs full range of movement in my shoulders..."

\section{Expressive}

Well-fitting garments give consumers positive outcomes, such as higher confidence, enhanced self-esteem, and improved psychological and social well-being (Anderson et al. 2000). These outcomes can be generated by well-fitting garments because clothing fit is strongly connected to consumers' mental status (Anderson et al. 2000; Shin 2013).

Self-esteem is one of the participants' most important expressive needs. In the comments, participants said:

"When I look good, I feel better and play better."

"Self-esteem is positively related to what I wear. I want to look good when I am playing tennis."

The female baby boomers perceived age appropriateness as another important expressive need for their tennis wear. In the comments, they said:

"I am 62. I feel as good as when I was 32, 42... no skimpy clothes for my age..."

"Age appropriate clothes for our age should not be too hard to find."

In the comments for individuality, personality, and professional look, the participants of our focus group said:

"I am comfortable with who I am and have the confidence to express it in my way..."

"I prefer individualism more than anything..."

"... revealing about my personality... I like classic and conservative clothes... This is me..."

"I want to look professional as I am competitive..."

\section{Aesthetic}

Investigating desires and preferences that suit baby boomers' aesthetic needs is important to create specific design aspects of their tennis wear. Similar to Chae and Evenson's (2013) study, female baby boomers wanted the combination of feminine and athletic features in their tennis wear to make their look more aesthetically pleasing. They also wanted the clothes to flatter their figures and make them look slimmer. In addition, unique styles and colorful garments were preferred to enhance overall aesthetic needs of the baby boomers' tennis wear. In the comments, the participants said:

".. lots of feminine styles for younger women but not for us..."

"I want something like the combination of feminine and athletic look... still looks 
strong and powerful..."

"I want the colors that make me look slimmer."

"I wanna look different... would not wear that if it is not flattering on me..."

"I want unique designs that make me feel more like me."

Consequently, we concluded that tennis players' garments should be designed with flexibility in the waist, chest, and shoulders. Further findings from this study revealed that usable pockets are another functional issue for mature female tennis players because they require a garment that allows them to carry or hold balls. This finding was also identified for mature female golf wear (Chae and Evenson 2013).

\section{Assessment of learning}

There were a total of 12 student groups, which were determined by the total number of design students in the class. Each group was composed of one fashion design major and two fashion merchandising majors. To stimulate a real-world work group closely, we randomly selected the teams.

Each student's learning and performance were assessed. Assessment of each student was included a semester-long group project (75\%), in-class activity participation (10\%), discussions (10\%), and attendance (5\%). The breakdown of the semester-long group project was as follows: research, including market, trend, and sourcing (20\%); storyboard (10\%); prototype development (20\%); tech pack (15\%); and peer evaluation (10\%). We then reflected on individual performance in the total group project grade, adding evaluations by each student's teammates as well as the instructor to the total project grade. The peer evaluation criteria included the following: reliably meeting deadlines for work in progress, contribution to the group, whether input for work-in-progress was provided promptly and with good faith, respect of each group member's opinions, and knowledge about assignments. The instructor's evaluation was followed by an observation of each student's class participation. Peer evaluations were gathered after every assignment and were presented by each team in class. The outcomes of peer evaluations were not revealed by group members.

We used four main evaluation criteria to assess student performance in this course: (a) project has a defined focus that uses appropriate methodology or theoretical framework and provides a solid conclusion (active research and sound reasoning); (b) the project indicates that information (e.g., citations, evaluation of sources, inclusion of sources) was used effectively to accomplish a specific purpose (information literacy); (c) project group members consider perspectives and positions, assess the data or evidence, and reach appropriate conclusions (critical thinking); and (d) project works as an academic project in scope, focus, analysis, deliberation, and execution (actual prototypes and oral presentations).

\section{Developing prototypes using the Watkins process}

Throughout the semester, each fashion design student group contributed to creating tennis wear prototypes for baby boomers following Watkins's (1988) prototype development process. The students conducted extensive research and focus group interviews and identified the problems expressed by the focus group participants (accept). The students then analyzed the information to determine user needs and wants regarding tennis wear (analyze); through the analysis process, they clarified information to pinpoint 
the main design problems and develop design criteria for the tennis wear prototypes (define).

The students developed storyboards that synthesized their market and trend research and style information into the line plan. They developed possible solutions to the identified problems and refined their ideas to arrive at the designs that best met the tennis wear needs of the target market. They digitally presented selected designs on storyboards to introduce their line of tennis wear, and one of the best designs in the line was selected as a prototype to develop (ideate and select).

In each group, the students developed draping and flat patterns to sew the muslin and then checked their muslin fittings on their fit models for the final garments. They created prototype tennis wear ensembles that met the needs of target consumers as identified in the focus group. The prototypes incorporated the design criteria (see Table 2) that the students had developed during the implementation process (implement). For instance, they selected stretch cotton jersey knits to provide comfort, breathability, and flexibility and a sleeveless design to offer free arm movement. The students used the baby boomers' preferred colors (e.g., cool colors) and styles to create unique, stylish, and aesthetically pleasing tennis wear that would help wearers feel good about themselves. In terms of evaluation, fit was identified as an important functional need among female baby boomers, so each group carefully evaluated appropriate fit with its own fit model for the prototypes; however, the students could not conduct wear tests because of the project's time constraints (evaluate).

To mirror apparel industry practices, students worked in teams. In addition to teamwork, each student group worked with a fit model, which provided a wide range of tangible and intangible benefits for learning about the product development process. This process enhanced students' perceived importance of and confidence in group work, which they could bring to the professional workplace.

We utilized a competition format for this semester-long project. At the end of the semester, the student groups presented their final projects to a panel of faculty judges from the fashion design and merchandising, business, and health departments, all of whom are baby boomers and play tennis regularly. The judges evaluated the projects

Table 2 FEA design criteria and garment attributes

\begin{tabular}{|c|c|c|}
\hline FEA needs & Design criteria & Clothing attributes \\
\hline Functional needs & $\begin{array}{l}\text { a. Comfort and fit } \\
\text { b. Breathability, durability, and utility } \\
\text { c. Free movement } \\
\text { d. Protection from the sun }\end{array}$ & $\begin{array}{l}\text { a. Provided by fabric choices (stretch cotton } \\
\text { jersey knits), appropriate fit for female baby } \\
\text { boomer body, and sewing quality for stretch } \\
\text { fabrics } \\
\text { b. Fabric choices (cotton and cotton blends); } \\
\text { Recommended TransDRY for future study } \\
\text { c. Sleeveless design for free arm movements } \\
\text { d. Recommended UV fabrics for future study }\end{array}$ \\
\hline Expressive needs & $\begin{array}{l}\text { a. Self-esteem and professional look } \\
\text { b. Age appropriateness, individuality, and } \\
\text { personality }\end{array}$ & $\begin{array}{l}\text { a. Improved fit, flattering to female baby } \\
\text { boomer body } \\
\text { b. Designed by baby boomers' design prefer- } \\
\text { ences }\end{array}$ \\
\hline Aesthetic needs & $\begin{array}{l}\text { a. Feminine and sporty look, strong and } \\
\text { powerful look, slimmer look, and flattering } \\
\text { b. Colorful and unique design }\end{array}$ & $\begin{array}{l}\text { a. Feminine silhouette, Improved fit, and flat- } \\
\text { tering to female baby boomer body } \\
\text { b. Designed by baby boomers' preferred colors } \\
\text { and styles }\end{array}$ \\
\hline
\end{tabular}


using the following criteria: research, creativity, quality (i.e., construction, tech pack [garment measurements], and fitting), presentation (i.e., storyboard and oral presentation), and readiness for production. The judges selected the top three teams, granting the first-place group a $\$ 500$ scholarship and those in the second- and third-place groups $\$ 400$ and $\$ 300$ scholarships, respectively (see Figs. 1, 2, 3, 4, 5). In addition, all students were invited by the Cotton Incorporated on a field trip to their headquarters in Cary, North Carolina.

\section{Discussion}

Using a conceptual framework, we used Lamb and Kallal's (1992) FEA consumer needs model and Watkins's design process (1988) to guide the development of prototype tennis wear for female baby boomers. The first objective of the study was to identify the clothing needs of female baby boomers who play tennis regularly. The focus group interviews using the FEA needs model initially helped the students understand the clothing requirements of their specific target audience. The interview findings supported the FEA needs as important design criteria for baby boomers' tennis wear. The students translated the FEA design standards into garment attributes and used them to develop prototype tennis wear for their fit models (see Table 2). The designs, which incorporated the FEA design criteria, supported the tennis wear needs expressed by the focus group

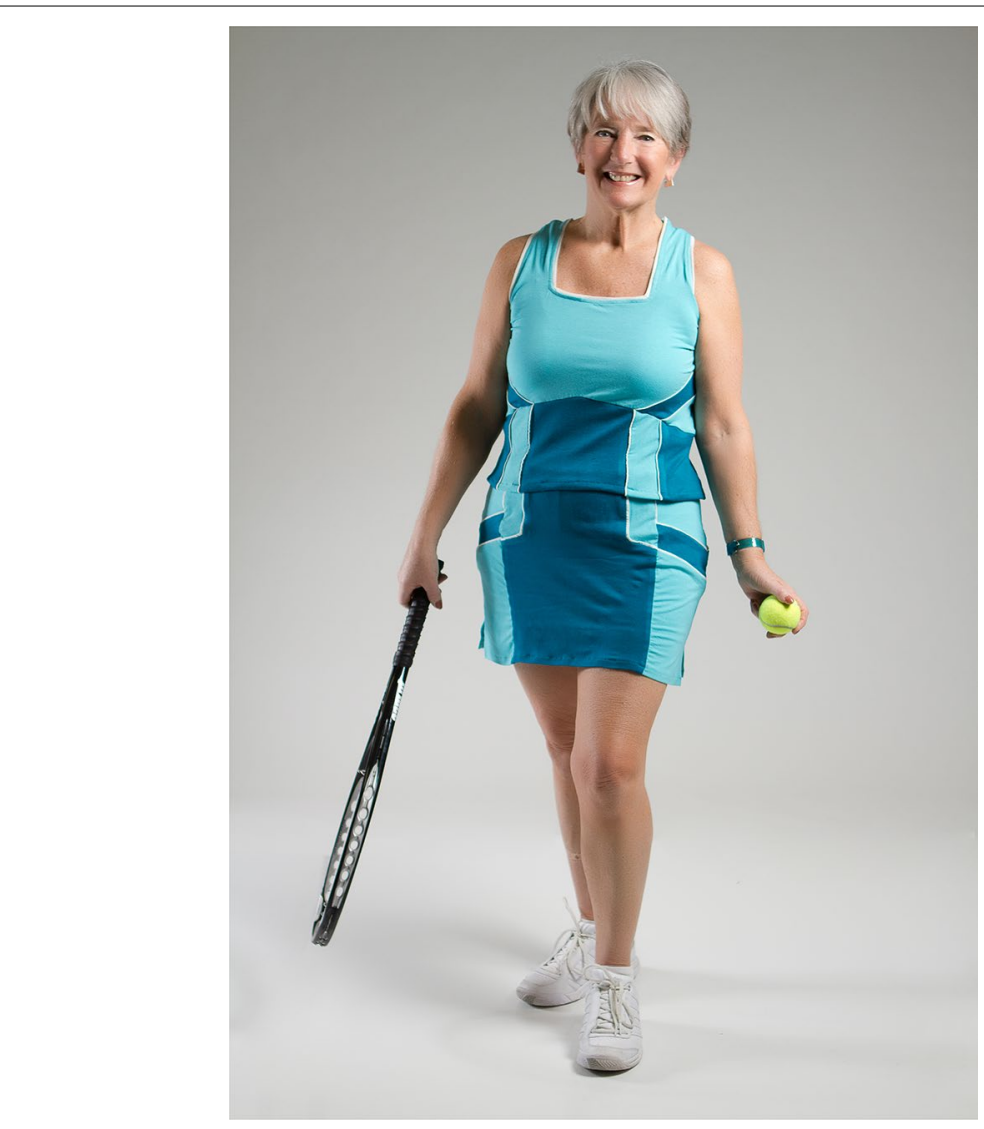

Fig. 1 1st place design (front view) 


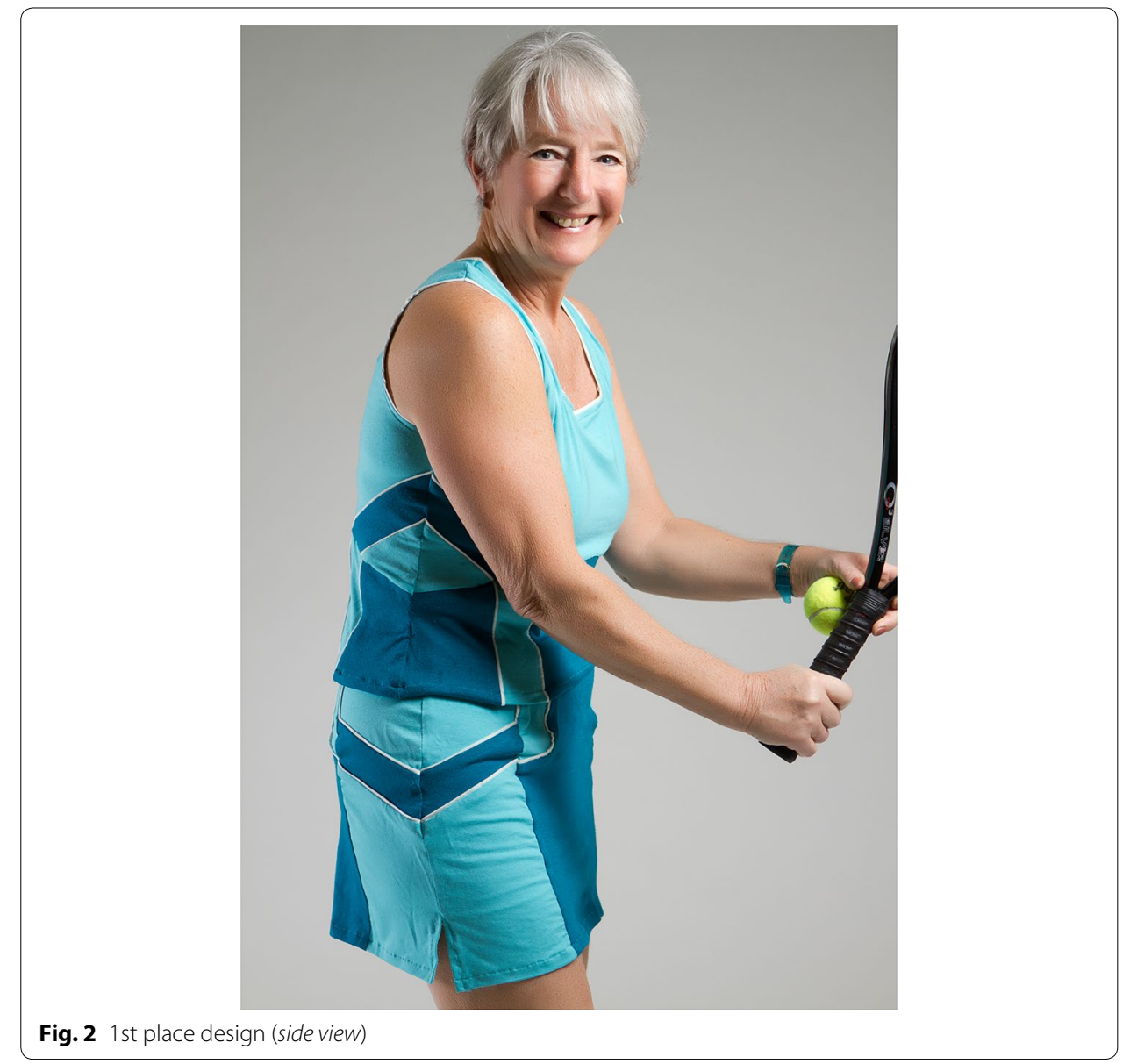

participants; the students used the most important requirements, such as comfort, fit, free movement, age appropriateness, and a feminine and sporty look, to improve the quality of the tennis wear. The students improved their problem-solving abilities and creativity throughout the process of applying well-balanced FEA design criteria to create suitable tennis wear that female baby boomers desired.

The second objective of the study was to familiarize students with the features and benefits of using cotton for active apparel through a semester-long product development assignment. The students' fabric choices were limited to cotton and cotton blends because of the Cotton Incorporated sponsorship; however, as many researchers previously established (Chae and Evenson 2013; Cotton Incorporated's Life Style Monitor 2012; Davis 1987; Forsthe and Thomas 1989; Robinson 2009), baby boomers prefer natural fibers such as cotton. Therefore, this project still represented a useful and innovative learning approach for the fashion students. Through this pedagogical consideration, the students gained knowledge of the features and benefits of cotton for tennis wear. By selecting appropriate fabrics (i.e., cotton or cotton blend jersey knits) that met the needs of female baby boomers, the students became more confident with the qualities of cotton (e.g., soft, breathable, comfortable, and easy to care for) to make the wearer look good and feel even better. These positive properties of cotton matched what the target 


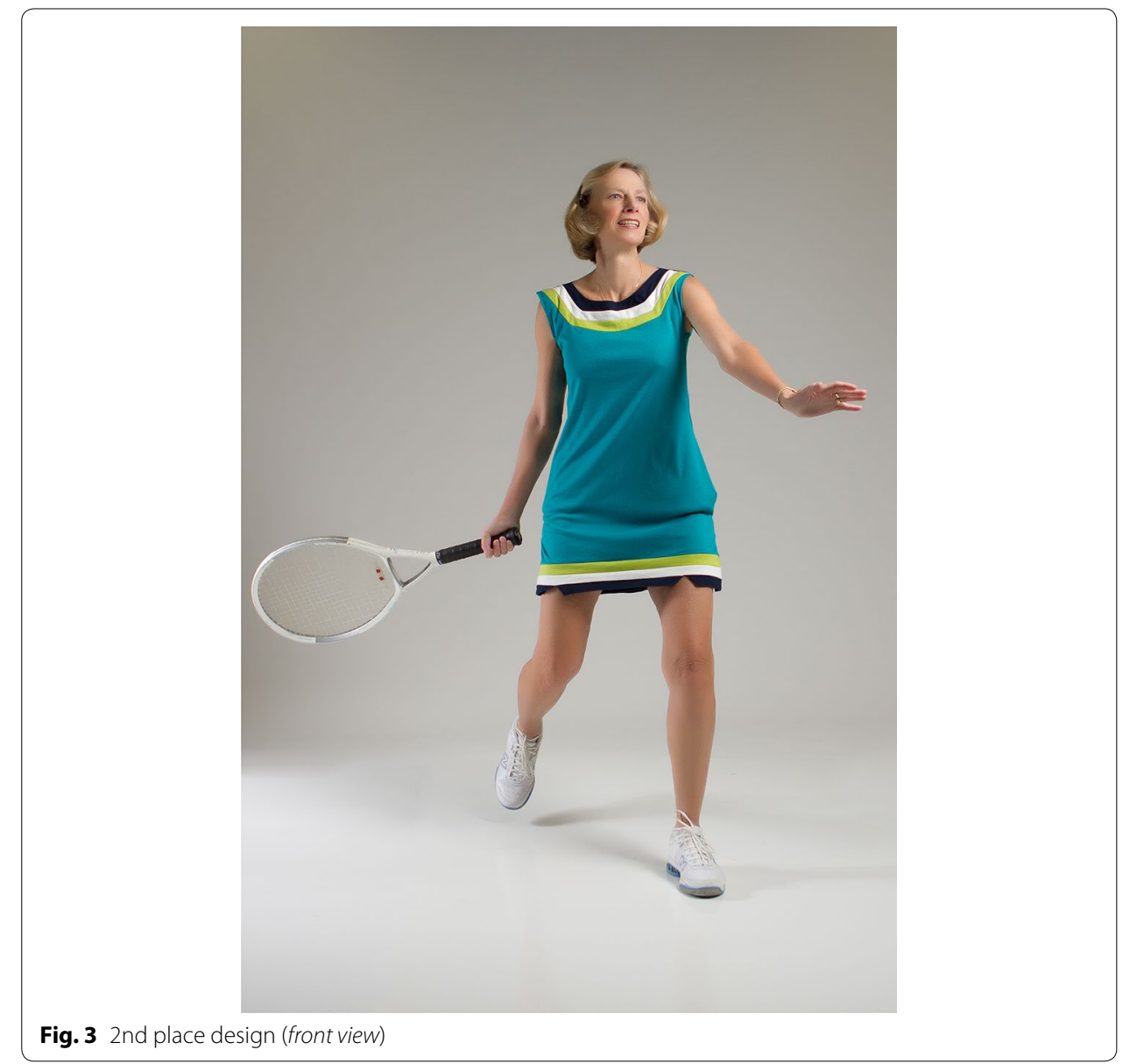

customers wanted. In particular, cotton blends with Spandex or Lycra were considered to be the best match with the design requirements for flexibility and movement because of their stretch and recovery properties.

To maximize the benefits of cotton for tennis wear, the students expanded their knowledge of cotton blends to enhance the use of sweat wicking and good stretching for free movement. TransDRY impressed the students because it enables cotton to expand its appeal regarding its performance utility in activewear. Although TransDRY fabrics are not yet available in local fabric stores or online, the students came to understand that wicking cotton/spandex blend fabrics (i.e., TransDRY) would be the best choice for tennis wear due to the improved fit and free movement around the arms and shoulders for female baby boomers who play tennis. Although the focus group participants found the UV ray protection fabrics to be ideal, they could not use those fabrics to develop prototypes because of their unavailability.

The third objective was to ensure that the study was based on industry-oriented learning. Teaching methods that incorporate industry-oriented instructions are important because they help students improve their creativity and problem-solving skills through practical examples, such as designing activewear for baby boomers. In addition to producing practical examples of clothing design for special target customers, the students 


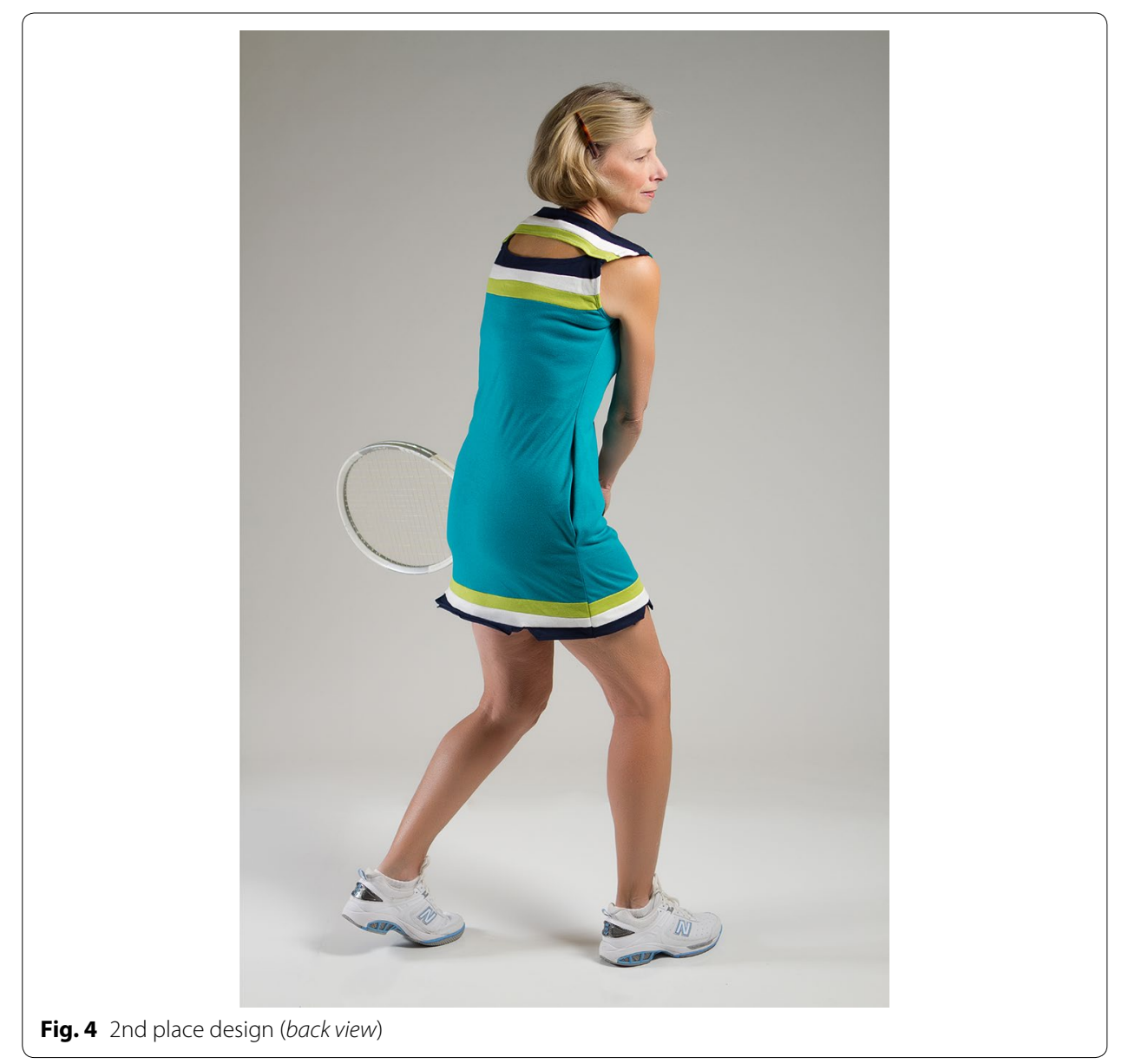

learned about the product development process by working with a team, discussing and communicating ideas, and putting solutions into action, as they will when they enter the fashion industry.

The most valuable teaching methods for this project included the focus group interview and the opportunities for students to work with fit models who could have been their potential target customers. The students worked with their teammates and fit models throughout the semester to complete the product development course successfully. Each of the 12 teams working on the project included a mix of fashion design and fashion merchandising majors and was paired with a USTA member. The students had to consider the individual preferences of the 12 women who volunteered to be fit models. For examples, one client, Mrs. Marden, asked for ruffles and sleeves, whereas another, Mrs. Launey, wanted a sleeveless design with a pocket to hold an extra tennis ball. Mrs. Vetter preferred her skirts to be fairly short, whereas Mrs. Conover requested a longer skirt. But all the clients agreed on the importance of comfort and ease of movement. In general, the fashion design students were used to working with standard dress forms, but they found that fittings were more demanding when working with real clients and different body shapes. In particular, the fashion design students in each group played important roles as technical designers, pattern makers, and sample makers. Each 


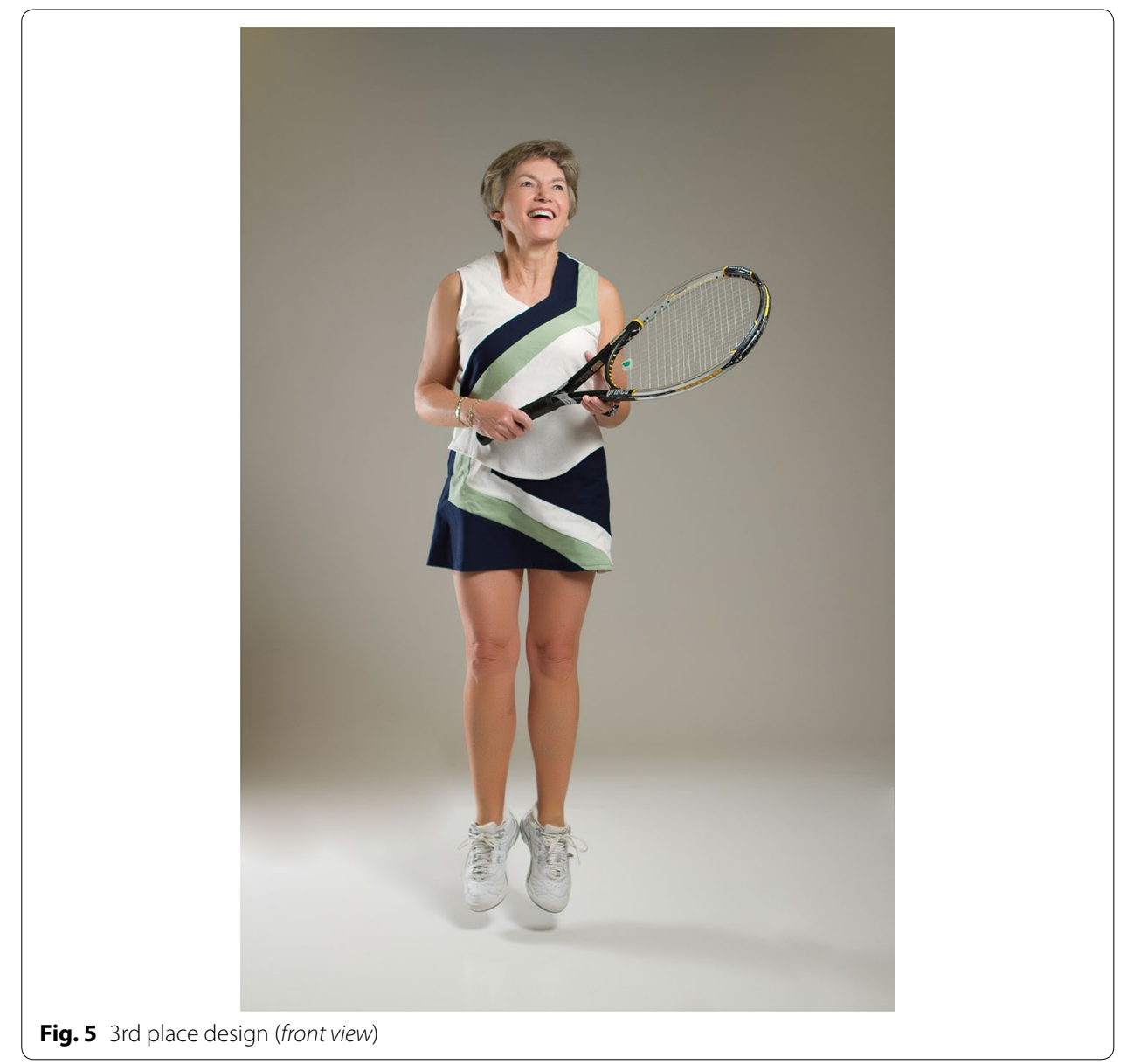

technical designer's job was to translate the design ideas into reality (i.e., to develop prototypes). The pattern makers created master patterns for the desired designs, and the sample makers became familiar with how to work with stretch fabrics (i.e., jersey knits) in terms of cutting, using appropriate stitches, sewing with a ballpoint needle, and finishing raw edges.

The students went back and forth from appropriate design and fitting solutions with their real clients, asking: "Do you like this length? How about the neckline?" The clients replied: "Can you make the shoulder strap narrower? I need a little more room in the arms." This cooperative learning process allowed the students to work together effectively and make decisions based on creativity, communication, and collaboration. Feedback from a panel of the judges was also helpful and effective for the students, allowing them to improve not only their academic performance but also gain self-confidence and enthusiasm for learning about product development. The students enjoyed a real-world experience in their product development course. The following are some of the students' comments:

- "I liked that the course was designed to simulate a 'real-life' situation." 
- "I thought the assignment of the mature female tennis wear was a great idea... I liked that we were making a product for a market that had a real need and that we had fit models to work with."

- "I liked the competition and the presentation, which I feel would be a big help to me in the real world. It was nice to have the ability to work with real people that would be a customer I would have to design for in the real world."

- "I liked that we would work in groups."

- "I now have a better understanding of what a product developer does and am interested in pursuing it as a career."

The manager of global supply chain marketing at Cotton Incorporated commented:

The Cotton Student Sponsorship Program is a highly competitive grant process... Cotton Incorporated was impressed by this project, in part because it was focused on baby boomers. This is a growing demographic with a large disposable income that often prefers cotton for its comfort and ease of care... The results of this project proved that they really learned how to listen to their consumers' needs (Oschwald, personal communication, January 6, 2011).

\section{Conclusion and recommendations}

The purpose of this study was twofold: (a) to assess the needs of female baby boomers regarding tennis wear to establish design criteria and (b) to develop prototypes of cotton tennis wear that incorporated the identified design criteria. The FEA standards to identify clothing issues and develop prototypes while simultaneously addressing the tennis wear needs of female baby boomers. The students used the Watkins design process to resolve the identified issues and guide the development of specific tennis garments, but they did not conduct wear tests to evaluate specific garment performance except for appropriate fit. This particular limitation suggests the need for future research using wear tests; prototype garments should be produced in a range of sizes and evaluated by more female baby boomers who play tennis to enhance the overall quality and performance.

Using a teaching approach that incorporated the baby boomer age and tennis wear in a real-world setting contributed to expose the fashion students to different perspectives of the extended fashion industry that need attention. This approach also helped the students overcome the challenges of prototype development through the semester-long group project with their teammates. Furthermore, giving the students a realistic, focused problem contributed to their portfolio development and increased their viability for employment. The project provided the students with an excellent learning experience in product development, thus increasing the value of their knowledge of-and potential for employment by-athletic apparel manufacturers such as Nike, Under Armour, Adidas, and Reebok. Future studies could explore how integrating realistic, focused problems in a specific target market, such as baby boomers, into a fashion study curriculum affects early-career product developers in the fashion industry.

Detailed knowledge of the properties of cotton, including its features and benefits, is critical for students who study apparel and textiles. Understanding the needs and interests of a specific target market whose fiber preferences may be determined by functional 
and aesthetic requirements that have both similarities to and differences from their own is essential for students who want to work in the apparel and textile industries. The ability to apply this understanding to the selection of specific textiles for the development of apparel targeted to a specific market is even more essential. Throughout this project, all fashion design and merchandising students were required to apply everything they learned in earlier courses to the product development process. Thus, they experienced real-world work in the development of tennis wear prototypes for mature women by working with real-world clients. Throughout this activity, from selecting cotton fibers to developing prototypes of their tennis wear, students continuously focused on the clothing needs of female baby boomer tennis consumers and the ability of cotton to fulfill those needs. In addition, because students were required to become familiar with the benefits of cotton throughout this project, they were encouraged to use cotton in their future designs. High performance fabrics such as TransDry and UV ray protection fabrics are recommended by this study to enhance the quality of clothing performance for tennis participants. This research project could be extended to other activities (e.g., biking, hiking, fitness, and well-being) that baby boomers are engaged with because they are still active and able to enjoy their vivacious life. Moreover, industry partnerships to manufacture actual clothing products through similar projects targeted at baby boomers would be valuable. The overall project contributed to meeting the goal to promote innovative teaching strategies that offer students educational opportunities that will help them live, work, compete, and prosper in a global community.

\section{Acknowledgements}

We would like to acknowledge the support of 12 mature women from the Mid-Atlantic region of the United States Tennis Association (USTA) for participating in our semester-long research project. We are also grateful to Cotton Incorporated for providing us with a grant to successfully pursue this research.

Competing interests

The author declares that she has no competing interests.

\section{Publisher's Note}

Springer Nature remains neutral with regard to jurisdictional claims in published maps and institutional affiliations.

Received: 15 September 2016 Accepted: 30 March 2017

Published online: 28 July 2017

\section{References}

Anderson, L. J., Brannon, E. L., Ulrich, P. V., Presley, A. B., Worondka, D., Grasso, M., et al. (2000). Understanding fitting preferences of female consumers: Development of an expert system to enhance accurate sizing selection. National Textile Center Annual Report, 98(8), 1-10.

Baby Boomers. (2017). In wikipedia. https://en.wikipedia.org/wiki/Baby_boomers. Accessed 31 July 2016.

Baker, J. (1995). How to introduce new ideas to people who don't want them. Presentation at the Mid-Regional Quality Conference of ASQC. Lincoln, NE.

Banning, J., \& Gam, H. (2013). Redesigning a fashion history course through team-based learning. Clothing and Textiles Research Journal, 31(3), 182-194.

Bye, E., \& Hakala, L. (2005). Sailing apparel for women: A design development care study. Clothing and Textiles Research Journal, 23(1), 45-55.

Chae, M., \& Evenson, S. (2013). Prototype development of golf wear for mature women. International Journal of Fashion Design, Technology, and Education. doi:10.1080/17543266.2013.837966.

Chumlea, W., Roche, A., \&Webb, P. (1984). Body size, subcuraneous fatness and total body fat in older adults. International Journal of Obesity, 8, 311-317.

Cotton Incorporated's Life Style Monitor (2012). Quality over quantity: Consumers weigh well-made apparel vs. fast fashion. http://wwd.com/globe-news/textiles/quality-over-quantity-consumers-weigh-well-made-apparel-vs-fastfashion-6549343/. Accessed 3 Mar 2016. 
Cotton Incorporated's Life Style Monitor (2015). A matter of comfort: Athleisure runs up the score with even more designers and collaborations. http://lifestylemonitor.cottoninc.com/a-matter-of-comfort/. 15 June 2016

Davis, L. L. (1987). Consumer use of label information in ratings of clothing quality and clothing fashionability. Clothing and Textiles Research Journal, 6(1), 8-14.

Domodharan, V.S., \& Rengarajan, V. (2007). Innovative methods of teaching. http://www.math.arizona.edu/ atp/Damodharan_Innovative_Methods.pdf. Accessed 13 Aug 2016.

Feiereisen, S. (2016). The pros and cons of each type of activewear fabric. http://www.cheatsheet.com/gear-style/proscons-activewear-fabric.html/?a=viewall. Accessed 25 Aug 2016.

Forsthe, S. M., \& Thomas, J. B. (1989). Natural, synthetic, and blended fiber contents: An investigation of consumer preferences and perceptions. Clothing and Textiles Research Journal, 7(3), 60-64.

Goldsberry, E., Shim, S., \& Reich, N. (1996). Women 55 years and older: Part II. Overall satisfaction and dissatisfaction with fit of ready-to-wear. Clothing and Textiles Research Journal, 14(3), 14-24.

Green, B. (2016). Ignoring the baby boomers in marketing is a business blunder. http://www.accesstourismnz.org.nz/ category/ageing-and-pwds/current-markets/page/14/. Accessed 1 Aug 2016.

Im, H., Hokanson, B., \& Johnson, K. (2015). Teaching creative thinking skills: A longitudinal study. Clothing and Textiles Research Journal, 33(2), 129-142.

Keiser, S., \& Garner, M. (2012). Beyond design: The synergy of apparel product development (3rd ed ed.). New York, NY: Fairchild.

Khon, I. (1996). Importance of posture and changed body configuration for garment fit for women aged 55 to 65. Unpublished master's thesis, Cornell University.

Kibria, G. (2014). What is innovative teaching? https://www.researchgate.net/post/What_is_innovative_teaching. Accessed 25 July 2016

Krenzer, G., Starr, C., \& Brandson, D. (2005). Development of a sports bra prototype: Patternworks international best solution to a patternmaking problem, 2000. Clothing and Textiles Research Journal, 23, 131-134.

LaBat, K., \& DeLong, M. (1990). Body cathexis and satisfaction with fit of apparel. Clothing and Textiles Research Journal, $8(2), 97-102$.

Lamb, J. M., \& Kallal, M. J. (1992). A conceptual framework for apparel design. Clothing and Textiles Research Journal, 10(2), $42-47$.

Lee, Y., Damhorst, M., Lee, M., Kozar, J., \& Parin, P. (2012). Older women's clothing fit and style concerns and their attitudes toward the use of 3D body scanning. Clothing and Textiles Research Journal, 30(2), 102-118.

Lunde, J. \& Wilhite, M. (1996). Innovative teaching and teaching improvement. To improve the academy. University of Nebraska-Lincoln. http://digitalcommons.unl.edu/podimproveacad/359. Accessed 13 Sept 2016.

Mullet, K. K. (1996). Built for two. Proceedings of the International Textile and Apparel Association (p. 149).

Pennington, B. (2006). Baby boomers stay active, and so do their doctors. The New York Times Sports. http://www. nytimes.com/2006/04/16/sports/baby-boomers-stay-active-and-so-do-their-doctors.html.

Pitimaneeyakul, U., Labat, K., \& DeLong, M. (2004). Knitwear product development process: A case study. Clothing and Textiles Research Journal, 22(3), 113-121.

Reich, N., \& Goldsberry, E. (1993). Development of body measurement tables for women 55 and older and the relationships to ready-to-wear garment size. ASTM Institute for Standards Research, ISR PCN 33-00006-18, ISR06. Philadelphia: American Society of Testing and Materials.

Robinson J. (2009). Still on top-cotton remains consumers'No.1 choice for clothing. http://www.cottongrower.com/marketing/market-analysis/still-on-top-cotton-remains-consumers-no-1-choice-for-clothing/. Accessed 5 May 2016.

Rosenbald-Walin, E., \& Karlsson, M. (1996). Clothing for the elderly at home and in nursing homes. Journal of Consumer Studies and Home Economics, 10, 343-356.

Salemi, M. (2002). An illustrated case for active learning. Southern Economic Journal, 68(3), 721-731.

Shin, E. (2013). Exploring consumers' fit perceptions and satisfaction with apparel fit in general. lowa State University. http://lib.dr.iastate.edu/cgi/viewcontent.cgi?article $=4191 \&$ context=etd.

Sontag, M. S. (1985). Comfort dimensions of actual and ideal insulative clothing for older women. Clothing and Textiles Research Journal, 4(1), 9-17.

Sprecher, M. (2005). Tennis boom time. Tennis industry magazine. http://www.tennisindustrymag.com/articles/2005/05/ tennis_boom_time.html. Accessed 28 Sept 2016.

Stone, M. (2011). The new older market. Tennis industry magazine. http://www.tennisindustrymag.com/articles/2011/08/19_the_new_older_market.html. Accessed 21 Sept 2016.

Watkins, S. (1988). Using the design process to teach functional apparel design. Clothing and Textiles Research Journal, 7(1), $10-14$.

What is TransDry technology? (2016). http://www.cottoninc.com/product/Product-Technology/Moisture-Management/ Transdry/Technology/.

Zhang, H. (2004). Activewear for older women who exercise regularly: A product development approach. http://mspace. lib.umanitoba.ca/handle/1993/17945. 